\title{
CARL SCHMITT E O CONCEITO LIMITE DO POLÍTICO
}

\author{
SCHMITT, Carl. The Concept of Political. Trad. George Schwab. \\ Chicago: Chicago University Press, 2007, 126p.
}

Washington Luiz Silva* wluizsilva@gmail.com

O público brasileiro que se interessa pela obra do jurista alemão Carl Schmitt sofre com a escassez de seus textos disponíveis em língua portuguesa. Apesar de alguns louváveis esforços que têm tentado suprir essa lacuna, algumas de suas obras mais expressivas seguem ainda sem serem traduzidas para o português, é o que ocorre com o conceito do político, que recebeu uma tradução no começo dos anos noventa, mas que infelizmente encontrase esgotada, ${ }^{1}$ restando ao leitor interessado nas idéias de Schmitt, recorrer às edições disponíveis em língua estrangeira como a edição organizada por George Schwab publicada pela editora da Universidade de Chicago.

Carl Schmitt é sem dúvida o maior pensador político do século XX e $o$ conceito do político é certamente de toda sua vasta bibliografia a obra mais conhecida, talvez por essa razão tenha permanecido durante um longo período como sendo o único livro do jurista traduzido para língua inglesa.

Este curto ensaio de Schmitt, é um dos grandes clássicos da filosofia política contemporânea, surgiu originalmente de uma conferência proferida na Deutsche Hochschuhle für Politik em Berlim por ocasião de um ciclo de conferências dedicado ao problema da democracia, sendo publicado com o título "Der Begriff des Politischen". Em 1927 (dois anos antes da crise de

* Mestrando em Filosofia, UFMG, Belo Horizonte, Brasil.

1 Uma nova tradução em português de "O Conceito do Político" acaba de ser publicada, pela editora Del Rey, infelizmente não tive acesso a ela antes da conclusão dessa resenha. 
1929, 6 anos antes da ascensão dos nazistas ao poder) no Archiv für Sozial Wissenchaft und Socialpolitik, tomo 58, n.1, pp.1-33 e reeditado na série Probleme des Demokratie, Politische Wissenchaft, Berlim, 19282, até ser publicado em1932, pela Duncker und Humblot, Munich, esta edição servirá de referência para a tradução de George Schwab. Por sua vez, Schwab é o grande responsável pela difusão da obra de Carl Schmitt em solo americano através de livros, artigos e traduções das suas obras mais importantes ${ }^{3}$. Nessa edição expandida, ora publicada pela Chicago University Press, aparecem também os comentários feitos por Leo Strauss. Este último ensaio foi publicado originalmente com o título: "Anmerkungen zu Carl Schmitt, Der Begriff des Politischen", no Archiv für Sozialwissenchaft und Sozialpolitik, vol.67, n.6, pp. 732-749, em 1932. A presença desse comentário de Strauss demonstra o alcance do debate que a obra provocou nos anos que se seguiram. Além do comentário de Strauss, a edição traz também a conferência que Schmitt proferiu em Barcelona em outubro de 1929, "Das Zeitalter der Neutralisierungen und Entpolitisierungen" (“A era das Neutralizações e Despolitizações”), publicada no mesmo ano na Europäische Revue e anexada à edição de 1932 do Conceito do Político.

É certo de que a tentativa de dar ao político um caráter autônomo separando-a dos demais campos da vida comum, não é algo novo, ao contrário, encontramos na história da filosofia política um grande número de obras e autores dedicados ao tema. A novidade trazida por Schmitt reside na forma com a qual o autor dá tratamento ao problema. Para pensar o político Schmitt parte do Estado abrindo o livro com a seguinte frase:

"O conceito de Estado pressupõe o conceito do político." 4

Com essa afirmação Schmitt demarca o território que sua reflexão pretende explorar nas páginas seguintes. Carl Schmitt é um pensador do Estado e como tal usa este como seu ponto de partida para pensar o político. A tarefa do livro será, portanto, descobrir a natureza do Estado reportando seu fundamento ao conceito do político. O Estado é o lugar por excelência do político, no pensamento de Schmitt e seu mundo é o mundo do Estado, além dele não há nada; ele concentra o monopólio da atividade política e sem este não existe política. O poder de decidir sobre amigo-inimigo recai between of 1921 and 1936. Nova York; Greenwood, 1989.

4 "The concept of state presupposes the concept of the political". Carl Schmitt, (2007, P.19). 
apenas sobre Estado, enquanto unidade política. Centrando o Foco no Estado como lugar próprio onde o político se manifesta Schmitt barra o que chama de Estado total, ou seja, a invasão do conteúdo dos diversos outros âmbitos da sociedade, na política. A idéia de Estado que ele defende é oposta a idéia de sociedade como fica evidenciado ao longo do livro. O conceito de sociedade não funda o conceito do político. Disso decorre a necessidade de recusa da proposição "tudo é política", que traz consigo a invasão de componentes que são estranhos ao político, tão comum na contemporaneidade, e que traz escondida uma tentativa de neutralizar o político. É contra essa "domesticação" ou "aprisionamento" do político que a obra se dedica a construir um conceito que preserve a autonomia do político, ou nas palavras de Schmitt: "o grau extremo do político". O resultado da penetração do social no político é perda da referência do Estado como lugar da política. O Estado total em Schmitt é mandado e administrado pela sociedade civil e não pelo Estado, que fica em segundo plano. O tema do Estado total que irá aparecer no conceito do político é o que há de mais representativo na crise contemporânea da forma política moderna. Diria o próprio Schmitt de que não há nada mais moderno do que a luta contra o político - o próprio Schmitt por seu conceito do político foi acusado de ser anti-moderno. É possível com isso afirmar que em última instância o tema que está colocado como pano de fundo da obra é o problema da autoridade, ou dito de outra maneira de sua destituição na era moderna. Com a dificuldade de se estabelecer com precisão o que é ou não é político, uma das tarefas do livro será, portanto a de apresentar um conceito que permita identificar o momento preciso do político, ou seja, como podemos reconhecer um fenômeno como sendo político ou não. Nas palavras de Schmitt:

(...) prover uma definição no sentido de um critério e não como uma definição exaustiva ou um conteúdo indicativo. ${ }^{5}$

O conceito do político é um critério, portanto servirá como norma de julgamento sem ter a pretensão de produzir um conceito que exprima todo o conteúdo político. O fundamental para Schmitt é que esse conceito seja claro e preciso.

Resta a Schmitt partir, então, para separar da política o que não lhe é próprio, distinguir o campo próprio da política dos demais campos do agir humano, tais como o estético, o econômico, o moral ou o religioso. Como nos 
lembra Galli, "o político é autônomo, inderivável, porque é o nome sintético da origem." "Seguindo o caminho trilhado por Maquiavel, Schmitt que dar à política um caráter autônomo - é, sobretudo sobre esse ponto que Strauss será mais contundente em suas críticas, denunciando a idéia de uma política autônoma e livre de valores - e liberar a teoria política do entrave que se origina da confusão entre a esfera política e os demais campos da ação humana. Ao reconhecer a necessidade de pensar a política em sua especificidade, Schmitt poderá ser filiado à tradição da filosofia política que tem como seus expoentes Maquiavel e Hobbes, autores dos quais se sente próximo.

Para isso, Carl Schmitt partirá direto para a idéia de fundamento e tentará responder a questão: qual é o objetivo do político? (no que diz respeito aos fundamentos da vida comum). Assim como o domínio da moral é determinado pelas noções de bem e mal, o estético pelas de belo e feio, o econômico pelas categorias do lucro, a política pode ser definida a partir da distinção amigoinimigo. Schmitt deixa claro que o inimigo ao qual se refere será sempre o inimigo público (hostis), a ênfase que o autor faz, é necessária para evitar que inimigo resvale no indivíduo (liberal) incapaz de produzir identidade e por conseqüência unidade. Há uma relação direta em Schmitt entre Identidade e unidade.

Este critério do político, porém, constitui um "conceito-limite", (ou caso de guerra) que é a mais extrema demonstração de inimizade e por conseqüência seu pressuposto último, que nos permite conhecer a natureza das formas políticas. É no caso limite que é manifesto todo caráter particular das oposições políticas. No livro Schmitt afirma que a guerra nos permite ter uma perspectiva privilegiada daquilo que não podemos perceber no cotidiano. Ela age ampliando nossa visão em relação ao político, o que em circunstâncias normais não seria possível. A perspectiva da guerra é, portanto a do caso de exceção, ela rompe a normalidade, essa perspectiva é, portanto reveladora, capaz de nos desvelar o ser do político. Em suma, a guerra traz a tona o político. Isso faz dela uma condição existencial da política. Não significa, porém que guerra seja finalidade da política, mas ela é uma possibilidade inscrita no ser da política. A possibilidade de haver guerra é o que Schmitt chama de político. Essa radicalidade que Schmitt emprega na formulação do critério do político é que no nosso entender confere originalidade a obra. O que está em jogo aqui é entender o político não simplesmente como conflito, mas pensá-lo numa perspectiva extrema, ou seja, em grau extremo.

6 GALLI, Carlo. Genealogia della política: Carl Schmitt e la crisi del pensero político moderno. Bologna: ॥ molino, 1996, P.738. 
O conflito para Schmitt é uma condição para a vida política como o é também em autores -cada um ao seu modo- como Hannah Arendt ou mesmo Claude Lefort, o que marca a obra de Schmitt é exatamente a dimensão que é dada ao conflito, afinal o antagonismo amigo-inimigo é de todos, o mais forte e intenso, que não afasta de si a possibilidade de provocar ou mesmo de sofrer a morte física. Mais uma vez ele é o grau extremo dirá Schmitt, é o conceito levado e aplicado ao seu limite, ao extremo. Na situação limite o humano é lançado na sua origem contingente, quer dizer, ele se priva de qualquer garantia e se expõe ao risco da morte. ${ }^{7} \mathrm{~A}$ decisão final será sempre sobre a vida do outro. Essa é a situação política por natureza.

Apesar da importância da guerra nessa formulação do político que Carl Schmitt faz isso não implica numa defesa da guerra como tal. Está claro no texto que ela não é o fundamento nem tão pouco a finalidade da política, também não faz parte da definição de amigo-inimigo, a guerra é possibilidade não conteúdo da política, ela é na verdade o reconhecimento de que a guerra está inscrita na possibilidade das relações humanas e é sobretudo uma recusa do pacifismo que vem como conseqüência do estado total, a célebre afirmação de Clausevitz de que a guerra é nada mais que prosseguimento da política por outros meios é resignificada por Schmitt.

Essa forma radical de pensar o político como "gradação", ou seja, como grau de intensidade do político, que Schmitt desenvolve se por um lado é a grande novidade na teoria política, por outro ela se mostra um perigo. Se o inimigo como quer Schmitt é desprovido de qualquer substância, há um vazio instaurado que necessita ser preenchido. Se o lugar que o inimigo ocupa é vazio, isso quer dizer que ele pode ser preenchido por qualquer elemento. Ocorre que o soberano como aquele que dentro da unidade política detém a prerrogativa de decidir sobre o inimigo, designa grupos a serem combatidos. O processo de decisão parece ser arbitrário. Essa característica da decisão a torna perigosa já que não está claro em Schmitt se ela tem um fundamento. A idéia da decisão é dizer que o lugar de onde ela surge não é visível aos olhos humanos. Rousseau o identifica como um lugar divino, mas nem ele próprio não consegui dar solução a esse problema. Se não é correto afirmar que o Estado schmittiano será necessariamente um Estado autoritário, todavia é correto dizermos que há uma porta aberta para o autoritarismo na sua formulação.

Carl Schmitt guarda uma vocação para a polêmica, e seu conceito do político ele próprio possui um sentido polêmico, como ele afirma: 
(...) todos os conceitos políticos, imagens, e termos tem um significado polêmico; Eles estão fundados sobre um conflito específico e estão destinados para uma situação concreta; e resulta (o qual manifesta ele próprio na guerra ou na revolução) em um agrupamento amigo-inimigo, e eles se voltam para dentro de abstrações vazias e fantasmagóricas quando essas situações desaparecem. ${ }^{8}$

A divisão "amigo-inimigo" que aparece no texto como critério para o político é também um posição metodológica, ou seja, serve como referencial metodológico. Esse caráter polêmico da escrita supõe ao autor saber contra quem, ou contra o quê escreve, para ser mais preciso o adversário ao qual sua argumentação se volta. É uma tomada de posição em relação a um adversário9. Como lembrou Claude Lefort em uma referência indireta a Carl Schmitt: "Proceder politicamente, para o filósofo, supõe levar em conta a oposição amigo-inimigo. (...) o filósofo é conduzido a escrever para seus amigos potenciais, ao mesmo tempo em que se dedica ao uso de astúcias para com seus inimigos reais ou potenciais." ${ }^{10}$ Schmitt leva ao extremo essa afirmação. Um desses inimigos que aparecem ao longo do livro servindo como marco teórico não somente do conceito do político, mas que estende-se a toda sua vasta produção teórica é o liberalismo e as concepções equivocadas no entender de Schmitt acerca do político. Concepções essas têm como alvo o Estado como unidade política retirando o caráter autônomo do político. O liberalismo será responsável por promover despolitizações subtraindo do Estado à capacidade decisória transformando inimigo em adversário, tomando dele sua prerrogativa de decidir sobre o inimigo e interpretar o caso limite.

O Conceito do Político preserva a clareza conceitual típica das obras do jurista alemão escritas no período correspondente ao período de Weimar, e Schmitt persegue essa clareza, pois ela é fundamental para seus objetivos já que o critério do político deve ser claro e inequívoco. É interessante notar que quanto mais Schmitt avança nessa clareza mais o leitor se questiona sobre a viabilidade desse conceito desse conceito tão extremo do político.

Carl Schmitt é nosso contemporâneo e como tal seus problemas e desafios teóricos ainda hoje são os mesmos desafios enfrentados por nossas sociedades liberais democráticas. Sua obra aponta para a fragilidade das nossas instituições

8 "(...) all political concepts, images, and terms have a polemical meaning. They are founded on a specific conflict and are bound to a concrete situation; the result (which manifests itself in war or revolution) in a friend-enemy grouping, and they turn into empty and ghostlike abstractions when this situation disappears." Carl Schmitt, (2007, P.30).

9 Sobre o significado do termo polêmico na obra de Carl Schmitt, cf. FERREIRA, Bernardo. O Risco do Político. Crítica ao liberalismo na teoria política de Carl Schmitt. Belo Horizonte: Editora UFMG, 2004, p.38-39.

10 LEFORT, Claude. Três notas sobre Leo Strauss, in: Os desafios da Escrita Política. São Paulo: Discurso Editorial, 1992, P.260. 
e ainda que não concordemos com suas soluções não podemos desconsiderar a relevância e pertinência de suas críticas. Schmitt é um daqueles autores que pela qualidade e profundidade da obra não nos passam despercebidos quando tomamos contato e o Conceito do Político é um dos mais importantes representantes dessa obra. Apesar de ter sido publicado pela primeira vez há cerca de oitenta anos, o texto não perdeu em nada seu vigor permanecendo atual nos dias de hoje. A obra nos oferece a oportunidade para pensarmos questões como: Ainda há política? Se a resposta for afirmativa, qual a forma que ele assume nos dias de hoje? No momento em que o político parece ter sido um problema superado e que por isso sua discussão tornou-se desnecessária, Schmitt nos oferece a oportunidade para trazer de volta esse debate. Além disso, O Conceito do Político constitui uma ótima porta de entrada para o pensamento de Carl Schmitt uma vez que podemos encontrar nele todas as suas idéias centrais, sem, contudo ser um resumo delas, o que torna esse livro leitura obrigatória para todos que se interessam por filosofia política. 